\title{
Development Coordination Disorder in Children Need for Information in a Transitional Post-Communist Country in Southeastern Europe
}

Juel Jarani

\section{Keida Ushtelenca}

Sports University of Tirana

\author{
Doi:10.5901/ajis.2014.v3n4p459
}

Abstract

The purpose of this essay/study is: to provide general information about past and actual situation in Albania (data from a study conducted in Tirana); to promote awareness of DCD in Albania in order to create a better understanding of the difficulties children and parents face. A large number of cities and rural areas in Albania do not have special education institutions and especially rural areas where resides about $46.3 \%$ of the population (Albanian Census Preliminary Results 2011). Effectiveness and work of the institutions leaves much to be desired. Also, heterogeneity of the children contingents and the problems they had to face has shown that these institutions have no clear profiles, an aspect which has result in lower quality work. Data from a cross sectional on 1177 children (619 boys and 558 girls) aged \{7-10 years old; grade 1-4) randomly selected in Tirana, using body coordination test for children-KTK (Kiphard and Schilling 1974, 2007), show that children categorized at normal level represented only $30.5 \%$ of the entire sample, while almost half of the sample were categorized below the normal level as having moderate motor disorder. To be concerned is the number of children that fall into the level of severe motor disorder $(19.4 \%)$ that will be the focus of future studies to be evaluated for having probably motor coordination disorder (possible DCD). In summary, increasing awareness of DCD and terminology used on parents and teachers is needed and providing effective and consistent management models based on a good evidence base to support families and children with DCD

Keywords: Development coordination disorder; conditions; children with coordination difficulties; identification of DCD; classification of $D C D$; fine and gross motor problems

\section{Introduction}

\subsection{Background of the children with coordination difficulties}

Over years different terms have been used to portray children with a predominant image of motor difficulties and to describe children with coordination difficulties such as: motorically deficient, developmental dyspraxia, clumsiness (Orton, 1937), perceptual-motor difficulties (Domrath, 1968), motor impaired (Whiting et al., 1969), and sensory integrative dysfunction (Ayres, 1972).

Information from a study of Kirby and Sugden (2007) refer to an earlier paper in the 1940s by Annell that describes this child as being:

$\therefore$. awkward in movements, poor at games, hopeless in dancing and gymnastics, bad writer and defective in concentration...'

The most widely internationally term used to describe these children is development coordination disorder (DCD). It comes out in both the Diagnostic and Statistical Manual for Mental Disorders (APA 2000, WHO 1992) and the International Classification of Diseases and Related Health Problems (WHO 1993, 1992).

Developmental coordination disorder has been known by many other names, some of which are still used today. It has been called clumsy child syndrome, clumsiness, and developmental disorder of motor function

Last decade there has been a substantial increase in awareness of the disorder, as well as in research relating to it since in London (1994, Ontario) finalizing with a consensus statement highlighting the existence of (DCD). More information was providing since 1987 and in 1994 (DSM-III-R/DSM-IV), describing DCD as the motor awkwardness displayed by a child of normal intelligence who is deficient in the motor coordination needed to execute task that are suitable for the age and is free of neurologic disease. 
The purpose of this study is: to provide general information about past and actual situation in Albania (data from a study conducted in Tirana); to promote awareness of DCD in Albania in order to create a better understanding of the difficulties children and parents face; to describe common characteristics of children with motor coordination difficulties especially development coordination disorder; and finally to provide a brief overview about identification, classification and assessments of children with DCD. The objective of this study was an assessment of gross motor coordination of Albanian children and identifying those children with motor development problems with an MQ score below 85 that represents a motor performance level below the 15th percentile that is considered problematic and might be a contingent of children with probably motor coordination disorder.

\subsection{An overview of the past situation in Albania}

The dealing process of disabled people in Albania has passed through two phases:

The first phase corresponds with the period of the communist regime creating a whole system of supports, where the policy during this time tried to hide the situation and was characterized by a prohibitory psychology from the family, passed through the society and finished to the government policies.

Significant change began during 1990 as a second phase and this is a period for the Albanian population to be opened where society became more attentive about the problems of disabled

Individuals, as is a great period for the changing in mentality of disabled child's families.

A study in Albania was conducting in 1998 by the Foundation for Disability Rights "National Opinion Survey" associated with the views that dominate the public Albanian people with disabilities. Interviewers were asked for the nature of the disabilities (medical, personal or social). About $32.8 \%$ had respond that the problem was purely medical, $10.2 \%$ considered it as a personal problem that is concerned only with the individual, $14.1 \%$ rate the issue as a social problem, $41.9 \%$ thought they were including the above three elements and only $1 \%$ of the 855 people surveyed did not provide any response.

Results from this survey show that about $20.5 \%$ of people asked showed family relation with a disabled person, which indicates that a relatively high number of Albanian society has relation and direct contact with this group of people. By analyzing the responses to other questions of this study data show that $83.3 \%$ of the Albanian public is convinced that this social group is neglected. About $43.9 \%$ of interviewers make responsible for failing economic constraints, $28.8 \%$ of them make responsible the political system, and about $34.2 \%$ of the interviewers show as responsible the mentality or culture that prevails in Albania.

The survey data analysis refer to a chaotic situation in this field, but at the same time they express an awareness and sensitivity to public opinion on the necessity of changes and creation of places or institution information or updates as part of the further democratization of Albanian society. Under the Albanian Constitution, a child enjoys, like every other citizen, equal rights before the law. Albanian has recognized the rights enshrined in the UN Convention on the Rights of the Child. Foundation for Disability Rights in Tirana (2002) conducted a survey for children with disabilities included in mainstream schools and concluded that general attitudes of teachers and children are positive. According to the data these children benefit from their experiences in mainstream and are not concerned for the classroom and school inclusion. About $90 \%$ of grade children want and feel able to help these children, but do not know the ways how to help them as well. Teachers in schools show that they generally are doing a great job but closed to the class, isolated in their classrooms, just cooperating among themselves to solve problems that they encountered in the classroom, lacking support services from the institution specialize for the children with disabilities or disorder.

A general glance is the impression that the Albanian society has a very positive attitude towards this social group even though it may be considered as one of the most problematic groups of the society. Albania has quite a small proportion of children in institutional care. Out of a population of 3.067 .740 Albania has only about 1200 children in institutions (MONEE Albania Country Analytical Report 2002).

\section{Methods}

This study research is a cross sectional study in children elementary schools $(\mathrm{N}=6)$ randomly selected in Tirana, Albania. A total of 1177 children (619 boys and 558 girls) aged \{7-10 years old; grade 1-4) made up the sample. Gross motor coordination was evaluated using body coordination test for children-KTK (Kiphard and Schilling 1974, 2007). 


\section{Procedures of the Test Perform in Albanian Children}

KTK focuses on gross motor coordination of both normal children without motor problems as well as children with motor and/or mental problems. The aim is to test gross motor coordination of children for general, medical, psychiatric, social and health-related purposes. The KTK allows an objective and straightforward evaluation of a child's gross motor coordination only, with only limited interference of the child's physical fitness, which discriminates this test from most other instruments. It is valid for 5-14 years old children. Each child completes each of the four KTK items (balancing backwards, one-legged obstacle jumping, jumping from side to side as well as sideway movements). For each task, points were given that made up the overall motor quotient (MQ) under consideration of gender and age factor. The overall MQ allows an assessment of the gross motor development in the following categories: 'not possible' (MQ <56), 'severe motor disorder' (MQ 56-70), 'moderate motor disorder' (MQ 71-85), 'normal' (MQ 86-115), 'good' (MQ 116-130) and 'high' (MQ 131-145). As stated by Kiphard and Schilling, in a normal population, an MQ score below 85 represents a motor performance level below the 15th percentile and is considered problematic. Motor therapy is then recommended in favor of the child's well-being. The KTK tests were performed in 1177 children.

\section{Results}

The results in percent (descriptive statistics) of the KTK are shown in Figure 1. The children that are categorized at normal level represent only $30.5 \%$ of the entire sample, while almost half of the sample participated in the study were categorized below the normal level as mention to the figure 1, having moderate motor disorder. To be concerned is the number of children that fall into the level of severe motor disorder (19.4\%) that will be the focus of future studies to be evaluated for having probably motor coordination disorder (possible DCD).

Figure 1. Descriptive statistics for the level of gross motor coordination in the following categories for the sample; results are shown in percent.

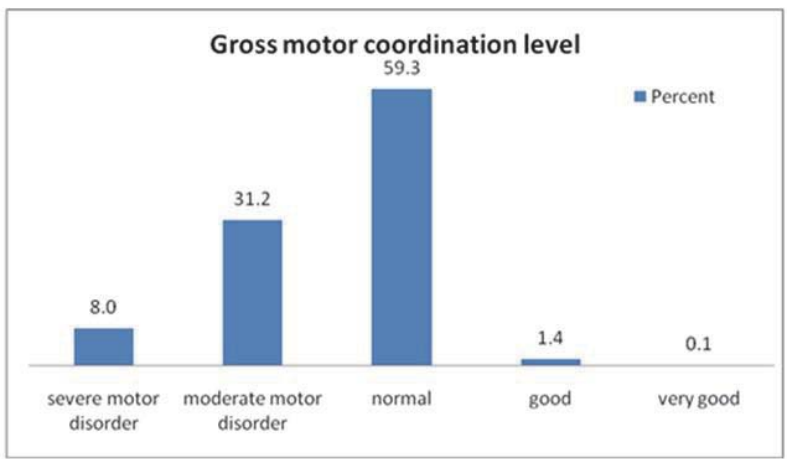

The boys (34.4\%) showed better results (figure 2) than girls (26.2\%) in the normal category. The MQ for the category of severe motor disorder for boys is $13.6 \%$ and for girls $25.9 \%$. 
Figure 2. Descriptive statistics for the level of gross motor coordination in the following categories of the sample for boys and girls; results are shown in percent.

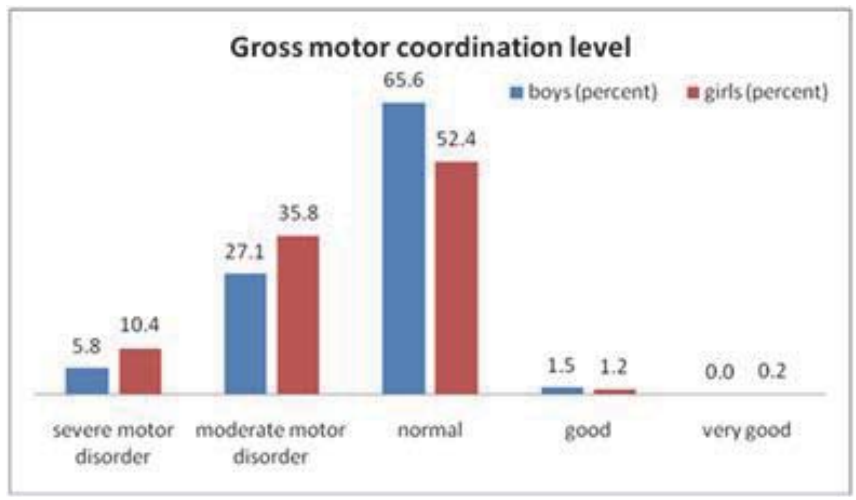

\section{Discussion}

For centuries, population in Albania has not had any facilities for deaf, blind and handicapped people. It was not until 1963 during the Communist regime that a school was opened in Tirana for this part of population. Later, in 1993, these people received instruction on an individual basis. Disabled and retarded children constitute a considerable part of the community of disabled people in Albania. A number of training and rehabilitation centers offer institutional services to retarded and disabled children but still a large number of cities and rural areas in Albania do not have special education institutions and especially rural areas where resides about $46.3 \%$ of the population (Albanian Census Preliminary Results 2011). In Albania for children with special needs (statistical data from 2002) are in function: 6 special schools, 3 day centers, 1 institution that deals with the children in special need, 3 residential (primarily those with mental retardation) and 2 national institutions; 1 for blind children and 1 for deaf children. While the last two institutions almost cover the needs of the country's institutions other institutions do not satisfy the requirements in this area and are insufficient in comparison with total needs. The centers provide care, therapy and education for children and young people with physical and learning disabilities, and multiple disabilities, except for the center in Tirana, which covers learning and multiple disabilities only. At the Tirana development center, the children go home for weekends. Data from the table 1 show the number of disabled children in these public institutions mention above.

Tab. 1 Number of disabled children in public institutional cares (MONEE Albania Country Analytical Report 2002).

\begin{tabular}{|l|l|l|l|}
\hline Year & $\begin{array}{l}\text { Children in residential } \\
\text { institutions } \\
\text { for physically/mentally } \\
\text { disabled }\end{array}$ & $\begin{array}{l}\text { Children in daily institutions } \\
\text { for physically/mentally } \\
\text { disabled }\end{array}$ & $\begin{array}{l}\text { Disabled children in child } \\
\text { homes, orphanages, boarding } \\
\text { schools }\end{array}$ \\
\hline 1998 & 111 & 91 & 60 \\
\hline 1999 & 107 & 52 & 56 \\
\hline 2000 & 97 & 54 & 61 \\
\hline 2001 & 103 & 59 & 57 \\
\hline
\end{tabular}

To meet the needs in this sector, a major contribution is being rendered by foundations and non-governmental organizations, which provide a wide range of services, bringing about qualitative changes in the conception and structure of offered services. Effectiveness and work in these institutions leaves much to be desired. Also, heterogeneity of the children contingents and the problems they had to face has shown that these institutions have no clear profiles, an aspect which has result in lower quality work. In conclusion the results of this study research show children categorized at normal level represented only $30.5 \%$ of the entire sample, while almost half of the sample were categorized below the normal level as having moderate motor disorder. To be concerned is the number of children that fall into the level of severe motor disorder (19.4\%) that will be the focus of future studies to be evaluated for having probably motor coordination disorder (possible DCD). 


\section{Future Direction}

Increasing awareness of DCD and terminology used on parents and teachers.

Providing effective and consistent management models based on a good evidence base to support families and children with DCD

Providing information about the actual panorama on Albanian children about this disorder

To differentiate (care and support) children with different type of disability in the actual institutions in Albania

\section{References}

American Psychiatric Association (1987) DSM-III-R Diagnostic and Statistical Manual of Mental Disorders. Washington DC.: American Psychiatric Association.

American Psychiatric Association (1994) DSM-IV Diagnostic and Statistical manual of Mental Disorders. Fourth Edition. Washington DC.: American Psychiatric Association.

American Psychiatric Association (2000) DSM-IV-TR. Diagnostic and Statistical Manual of Mental Disorders. Fourth Edition. Text Revision. Washington, DC.: American Psychiatric Association.

Domrath, R.P. (1968). Constructional praxis and visual perception in school children. Journal of Consulting and Clinical Psychology, 32, 186-192.

Foundation for Disability Rights (2002). Albanian to school integration process. Study on integration of children with disabilities in mainstream schools. Funded by NOVIB - Netherlands, Tirana 2002

Fshdp (1998). National survey - "Public Opinion and People with Disabilities", Tirana.

Kirby. A, Sugden D (2007). Children with developmental coordination disorders. Journal of the royal society of medicine; 100:182-186

Kiphard EJ, Schilling F (1974). Ko"rperkoordinationstest fu" $r$ Kinder. Weinheim: Beltz Test GmbH.

Kiphard EJ, Schilling F (2007). Ko" rperkoordinationstest fu" $r$ Kinder. 2. U" berarbeitete und erga" nzte Auflage. Weinheim: Beltz Test $\mathrm{GmbH}$.

Gibbs J, Appleton J, Appleton R (2007). Dyspraxia or developmental coordination disorder? Unraveling the enigma. Arch Dis Child:92:534-9.

Geuze, R.H. (2005). Motor impairment in DCD and activities of daily living. In D. Sugden \& M. Chambers (Eds.), Children with Developmental Coordination Disorder (pp. 19-46). London: Whurr Publishers, Ltd.

Mari M, Castiello U, Marks D, Marraffa C, Prior M (2003). The reach-to-grasp movement in children with autism spectrum disorder. Philos Trans R Soc Lond B Biol Sci; 358(1430):393- 403

Miller, L.T., Missiuna, C.A., Macnab, J.J., Malloy- Miller, T., \& Polatajko, H.J. (2001). Clinical description of children with Developmental Coordination Disorder. Canadian Journal of Occupational Therapy, 68, 5-15.

Missiuna. Ch (2003). Children with Developmental Coordination Disorder: At Home and in the Classroom. CanChild, Centre for Childhood Disability Research. 1-12

Monee Country Analytical Report 2002. UNICEF Innocenti Research Centre. Children and disability in Albania. United nation children's fund. Institute of Statistics, INSTAT, Tirana

Orton, S.T. (1937). Reading, writing and speech problems in children. New York: W. W. Norton \& Co.

Visser J (2003). Developmental coordination disorder: a review of research on subtypes and comorbidities. Hum Mov Sci;22:479-93.

Whiting, H.T.A., Clarke, T.A., \& Morris, P.R.A. (1969). A clinical validation of the Stott Test of Motor Impairment. British Journal of Social and Clinical Psychology, 8, 270-274.

World Health Organization International Statistical Classification of Diseases and Related Health Problems (1992), 10th ed, Vol. 1, ICD10. Geneva

World Health Organization Classification of Mental and Behavioural Disorders (1992): Clinical Descriptions and Diagnostic Guidelines. Geneva

World Health Organization Classification of Mental and Behavioural Disorders (1993): Diagnostic Criteria for Research. Geneva:

Wright, H. C. \& Sugden, D. A. (1996) A two-step procedure for the identification of children with developmental co-ordination disorder in Singapore. Developmental Medicine and Child Neurology, 38, 1099-1105. 
